\title{
Razões para festejar o teatro no Canadá (Ontário)
}

\author{
Maria Helena Serôdio
}

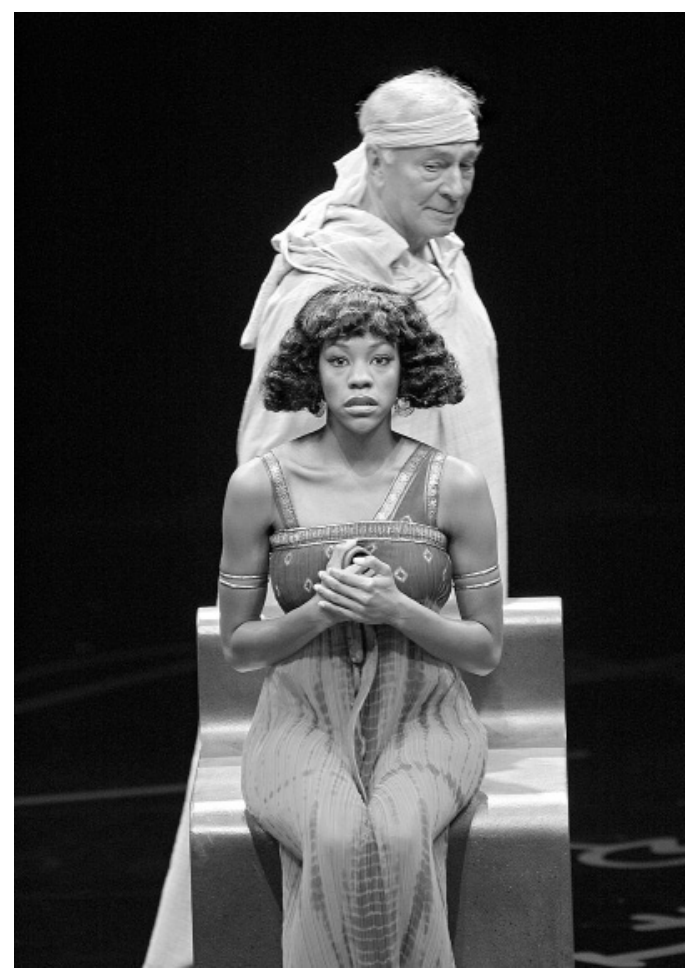

No contexto de um encontro em Toronto da Associação Internacional de Críticos de Teatro que propunha a críticos de vários países uma investigação em torno de possíveis tradições nacionais do "comentário de teatro" (integrando crítica, notícia, ensaio ou polémica aberta) para uma futura publicação com a chancela dessa organização, foi possivel perceber algumas das linhas de funcionamento do teatro canadiano. Não apenas através de algumas comunicações (de críticos como Michel Vaïs, Anton Wagner e Kamal alSolaylee) e da interessante publicação sobre a história do teatro canadiano - organizada por Don Rubin -

oportunamente reimpressa, mas também através de um intenso périplo por algumas das produções canadianas que se ofereciam ao público no início do mês de Outubro.

Foi assim que, por entre criações de recorte mais experimental na cidade de Toronto- na produção de peças originais de autores contemporâneos, como é o caso do Factory Theatre, ou na apresentação de um espectáculo de ópera rock de pendor expressionista, como se mostrou no Tarragon Theatre -, foi interessante reconhecer que duas iniciativas "festivas" atraem para as pequenas cidades

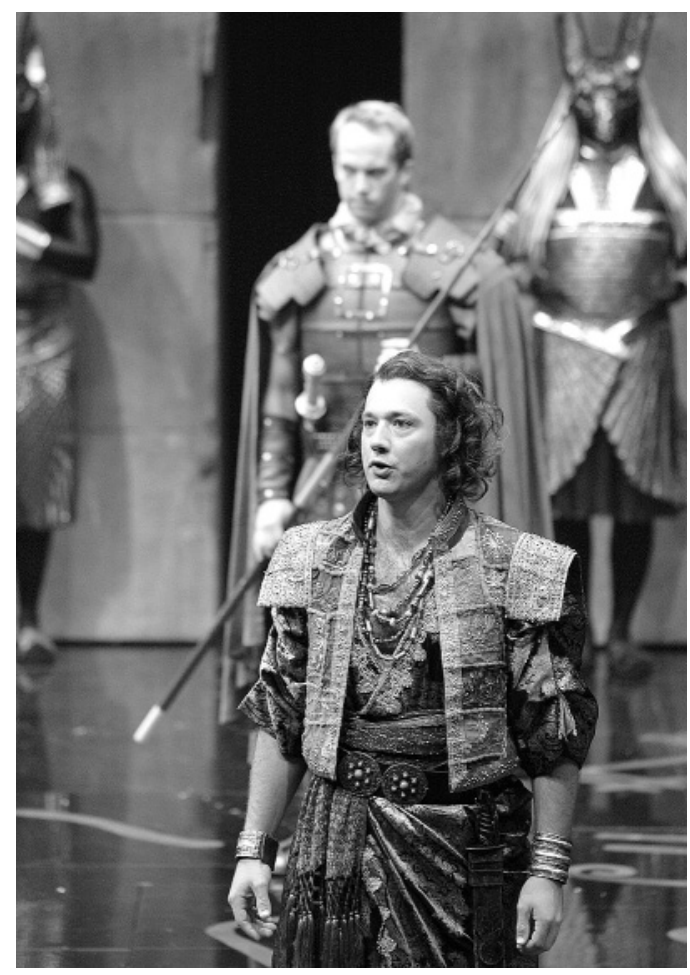

César e Cleópatra de George Bernard Shaw, enc. Des McAnuff, Stratford Shakespeare Festival 2008 (< Christopher Plummer e Nikki M. James; $>$ Gordon S. Miller e lan Lake), fot. David Hou. de Stratford e de Niagara-on-the-Lake, ambas integradas numa invulgar beleza paisagística, públicos diversos - na idade e condição - para diariamente verem espectáculos em que texto e encenação se ligam estreitamente num desejado e assumido preceito canónico de exposição cénica.

No Factory Theatre, a peça da jovem canadiana Charlotte Corbeil-Coleman - Scratch (Coçar) - falava dos medos e desejos de uma adolescente justapondo - de forma irónica, mas igualmente sensivel - a descoberta da sexualidade e a revelação da condição terminal da mãe numa despojada mas eficiente encenação de Ahdri Zhina Mandiela; enquanto no Tarragon Theatre se oferecia uma produção do November Theatre, de Edmonton, baseada na invenção artística de Tom Waits, William Burroughs e Robert Wilson, The Black Rider: The Casting of the Magic Bullets ( 0 cavaleiro negro: 0 disparo das balas mágicas). Inspirado num conto popular alemão que envolve uma jovem filha de caçador, um noivo imposto (pelo pai), um pretendente (que terá de provar que é um bom caçador) e uma figura demoníaca (Peg Leg), o espectáculo refaz este pacto faustiano de uma forma brilhante, sem grande 




aparato operático, antes com um apuro artístico notável e um apreciável "brilho luciferiano", como referiu o crítico Robert Enright da CBS (rádio e TV). Montado em 1998 (um ano depois da morte de Burroughs) e desde então distinguido com diversos prémios, o espectáculo dirigido por Ron Jenkins traz à cena um universo entre o grotesco e a alucinação, entre a paródia "gótica" e a condição de viciado, com interpretações inesqueciveis sobretudo de Michael Scholar Jr. (diabolicamente sedutor como Peg Leg) e Kevin Corey (como o pretendente de traços rústicos e de uma prodigiosa agilidade). 0 elenco oferecia, de resto, composições interpretativas de grande fôlego, revelando um domínio seguro do canto e da fisicalidade, em que aspectos clownescos e uma curiosa proximidade da cena e do público (com os músicos - a Devil's Rubato Band também fortemente maquilhados e num diminuto espaço entre o palco e a sala) conduziam a um tipo de relação inspirada no cabaré de tonalidade expressionista.

Num sentido muito particular de "festival", as cidades de Stratford e de Niagara-on-the-Lake, ambas na província de Ontário, refazem anualmente - sob o nome que tradicionalmente na Europa se refere uma iniciativa pontual de carácter festivo a que se reporta uma amostra de produções - uma longa temporada dedicada especialmente a Shakespeare e a George Bernard Shaw, respectivamente, embora em ambos os casos admitindo outros autores e investindo geralmente em textos de claro valor canónico e produções de grande aparato teatral em cenário e figurinos.

Em Stratford é a cidade natal de Shakespeare que se celebra numa desejada reencenação paisagística: lá está o rio Avon, os belos cisnes e patos que o povoam, bem como os canteiros de flores coloridas pontuando o extenso e impecável relvado que rodeia os diversos edificios de teatro que revelam a condição festiva desta cidade-teatro: o Festival Theatre (com palco em redondo), o Avon Theatre, o Tom Patterson Theatre, o Studio Theatre e o Festival Pavilion. Efervescente de movimentação, o festival acolhe um público diversificado que é maioritariamente constituido quer por estudantes em jornada programada (e são sempre muitos e, de um modo geral, efusivos no interesse que revelam), quer por adultos que escolhem ir avulsamente a espectáculos seleccionados ou que decidem combinar a condição de espectadores a uma temporada de descanso e férias nesta aprazivel cidadezinha do Ontário. Na grande sala do Festival Theatre foi possivel ver, entre outros espectáculos de revisitação shakespeariana (todos a merecerem um programa bem organizado e com imagens atraentes), uma aparatosa encenação de Hamlet pelo britânico Adrian Noble e uma luxuosa produção de César e Cleópatra, de Shaw, com a participação de Christopher Plummer, o Capitão von Trapp do memorável filme de Robert Wise Música no coração (1965).

Em Hamlet, Noble exibia uma operática reinvenção cénica em versão pós-moderna: apoiava-se numa construção cenográfica (de Santo Loquasto) de grande aparato e com prodigiosas mudanças de adereços, e ia vestindo as personagens em sucessivos figurinos históricos desde 0 tempo imperial de finais do séc. XIX até à mais próxima guerra das trincheiras, numa acelerada corrida cronológica que também se exibia de forma exuberante nas toilettes das actrizes. Com um ritmo muito vivo e uma robusta movimentação cénica, o espectáculo expunha algumas soluções curiosas de enquadramento, como a irrupção dos actores ambulantes em cena ou o uso de inesperados pontos de luz. 0 trabalho de actores parecia relativamente banal e a espectacularidade desta produção cumpria não apenas o desejo de exibir um escopo de alargados meios técnicos, mas também o indisfarçável desejo de uma produção festiva, ou seja, de uma pouco disfarçada exuberância visual.

Idêntica solução de grande aparato cenográfico e de faustosos figurinos foi a encenação de César e Cleópatra que Des McAnuff (Director Artistico do Festival) concebeu para o encontro em palco de um actor de créditos artísticos firmados em teatro e cinema, Christopher Plummer, e a jovem actriz revelação Nikki M. James, formada pela Tisch School of the Arts, da Universidade de Nova lorque. Partindo de um texto brilhante - de astúcia política e ironia intelectual 


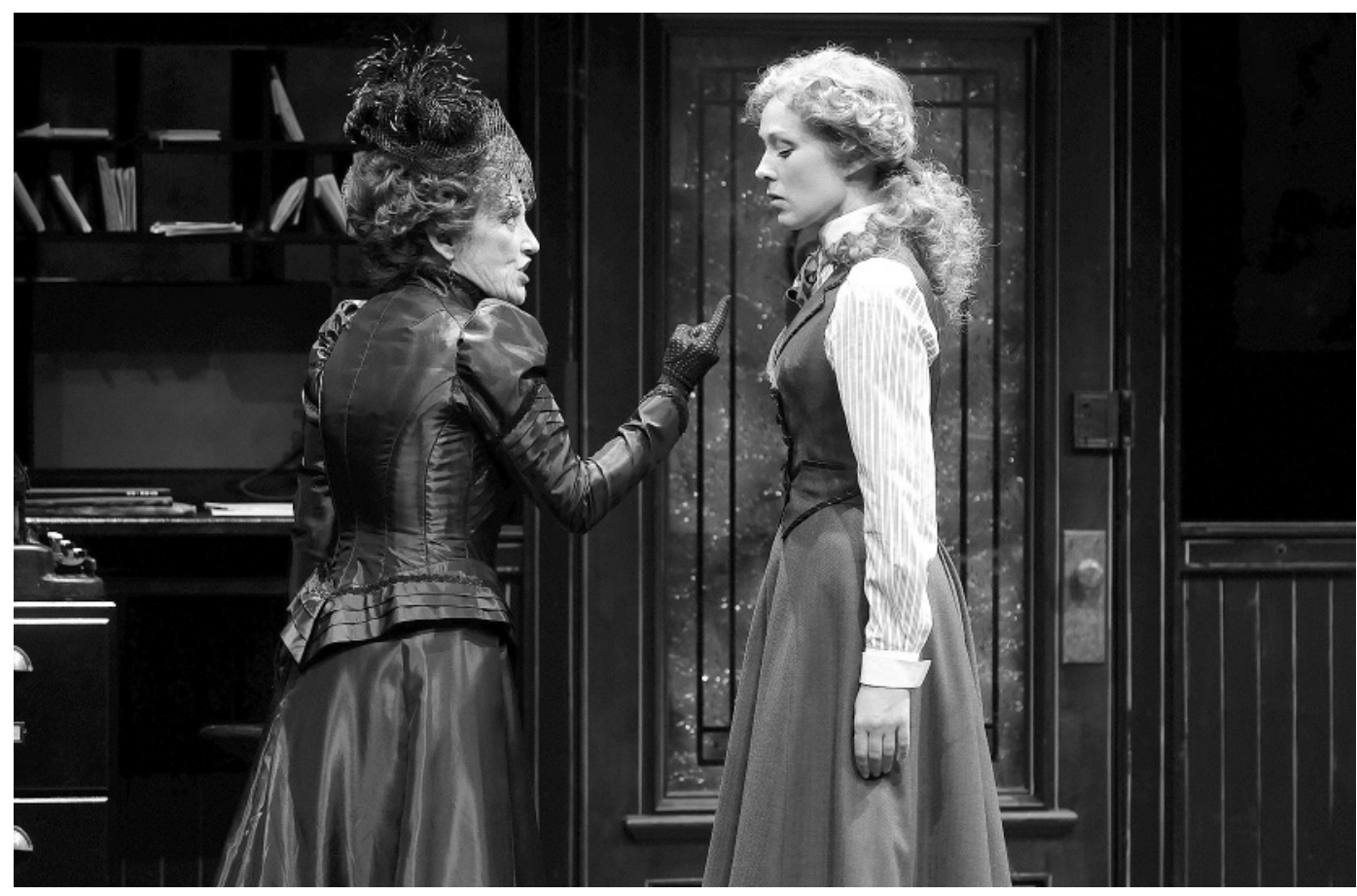

A profissão da Sra.

Warren,

de George Bernard Shaw, enc. Jackie Maxwell,

Shaw Festival 2008

(< Mary Haney

e Moya O'Connell;

$\checkmark$ Benedict Campbell

e Andrew Bunker),

fot. Emily Cooper.

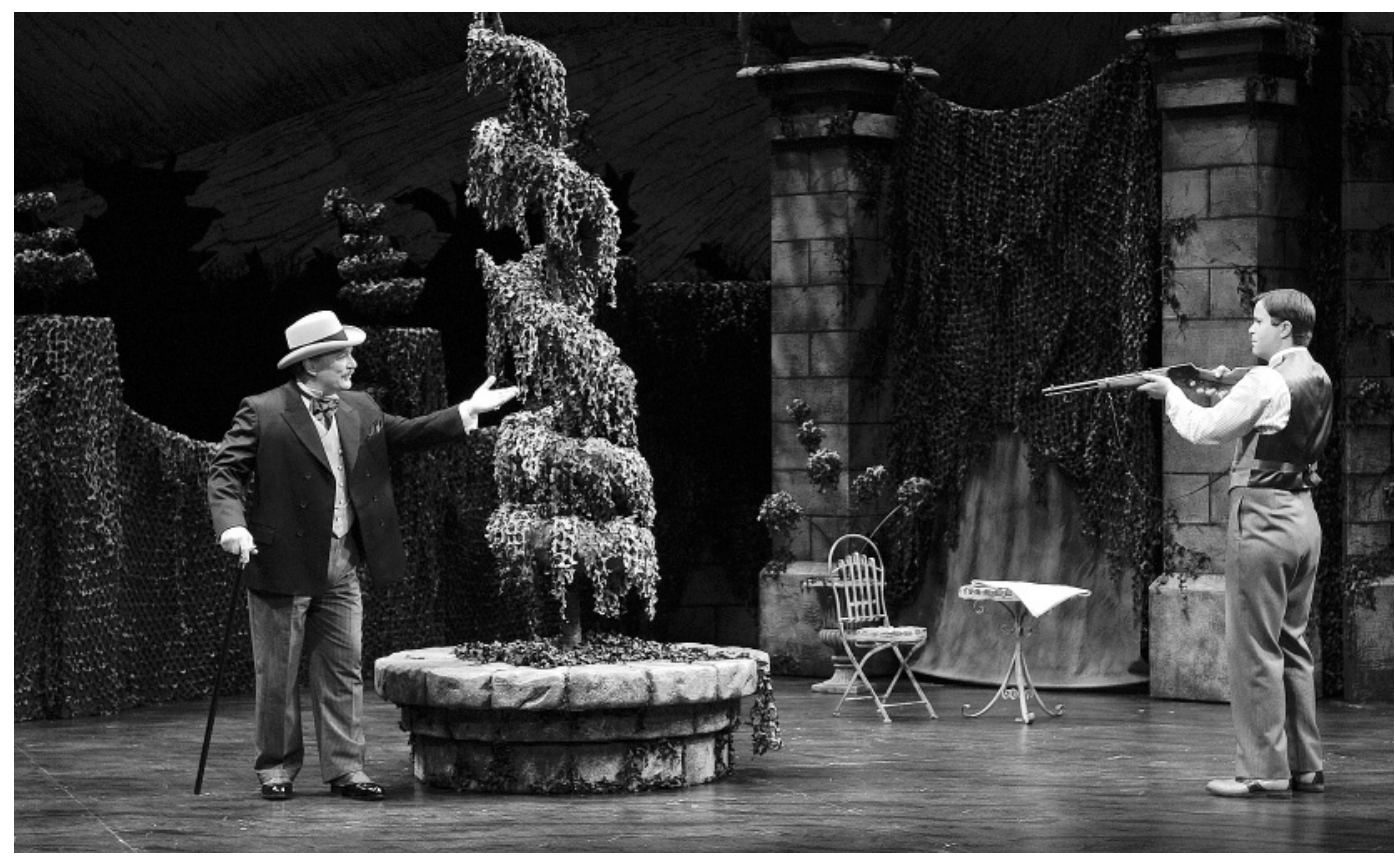

- que Shaw escreveu em 1898, o espectáculo reactualizava uma história inventada em torno do que poderia ser o ensinamento político que o imperador Júlio César passou à jovem Cleópatra (uma adolescente de dezasseis anos e não de 21 anos como historicamente terá ocorrido - na invenção de Shaw). Neste texto, que parecia parodiar os melodramas vitorianos no esboço algo fabuloso, Shaw desenvolveu a verve irónica que Bertolt Brecht tanto apreciava no autor irlandês de sentimentos socialistas (de pendor fabiano), um aspecto que transparecia na produção deste Festival Shakespeare. Apesar de ser esse o cerne verdadeiramente shaviano do espectáculo, o cenógrafo (Robert Brill) e o figurinista (Paul Tazewell) ajudaram e muito na criação de um espectáculo que quis ser uma degustação visual de grande e elaborado requinte.

Dir-se-á que, em boa verdade, o excesso de aparato cénico é demasiado impositivo para que se possa apreciar o trabalho de composição dos actores, quase parecendo, de resto, que a criação teatral se esgota nessa componente "exterior" à arte do actor. 0 que até pode ser verdade. Todavia, não é de excluir que esta seja a "materialidade" que agrada aos muitos mecenas que apoiam o teatro no Canadá, por aí cedendo ao brilho acrescentado (como imposto a pagar) a que obriga o sistema. E que, apesar de tudo, ele se conforma a um gosto médio que pode carrear para as salas de espectáculo um público que se deleita com a feérie que o cinema oferece e com os desfiles em passerelles que a televisão não se cansa de mostrar. E talvez que desse público - regular, de médio gosto e interesse - se desenvolva um núcleo capaz de ir mais além no desejo de uma mais exigente elaboração teatral: quer no trabalho de interiorização no trabalho do actor, quer 
As raposas de Lillian Helman enc. Eda Holmes, Shaw Festival 2008 (Laurie Paton),

fot. David Cooper.
O cavaleiro negro de Tom Waits, William Burroughs e Robert Wilson enc. Ron Jenkins, November Theatre 1998 (Michael Scholar Jr. e Kevin Corey), fot. Adam PW Smith na invenção de cariz mais ousado e experimental.

Efeitos visuais igualmente esmerados marcavam também as produções do Shaw Festival na pacata cidadezinha de Niagara-on-the-Lake, a escassos quilómetros das cataratas de Niagara. Mas a tonalidade era mais de um realismo cénico evocador do final do séc. XIX e início do séc. $X X$, o que, de algum modo, se esperava de um repertório que incluía A profissão da Sr. ${ }^{a}$ Warren (Mrs Warren's Profession, 1893), de George Bernard Shaw, As raposas (The Little Foxes, 1939), de Lillian Hellman, ou Está lá fora um inspector (An Inspector Calls, 1946), de J. B. Priestley. Decorrendo também em diferentes teatros Festival Theatre, Royal George Theatre e Court House Theatre - era visivel o cuidado posto na preparação dos programas (distribuidos gratuitamente) e a elaboração de grande requinte dos cenários e figurinos. E se o texto de Priestley se prestava a um trabalho que na envolvência de uma grande mansão vitoriana podia desenhar um tablado que se movimentava lentamente como um mostrador de um relógio a apontar uma significativa interrogação sobre a não coincidência entre o tempo cronológico e o psicológico, a cenografia para a peça de Shaw era um clamoroso efeito de monumentalidade que quase exigia o "assombro" do espectador, para além da atmosfera de época que também se recriava através de figurinos e maquilhagem. De encontro a estas evocações de sabor britânico, destacava-se a memória de uma familia sulista americana - os Hubbard - que Lillian Hellman retratou na sua peça, ao mesmo tempo que denunciava a ambição desenfreada, bem como a despudorada cobiça que não olhava a meios para realizar uma especulação financeira, coisa que vem alimentando o cinema (e, actualmente, esvaziando os créditos bancários) e as várias séries televisivas de um figurado americanismo.

Recordar as peças que se reportam a um realismo oitocentista ou novecentista, bem como as que jubilosamente se prestam a um shakespearianismo de vivacidade, turbulência e festiva evocação de um vasto espectro social é um procedimento que se conforma à


sedimentação (que pode ser de aprisionamento) de um cânone teatral. Mas não deixa de, por isso mesmo, ser a base de um conhecimento que melhor permite - a um outro nivel de reinvenção - uma recriação artística que o reelabore, que o ponha em causa ou que o transfigure em mais inventivas desordens estéticas de sentido mais urgente.

\section{Referências bibliográficas}

RUBIN, Don (ed.) (2007), Canadian Theatre History: Selected Readings (2004), Toronto, Playwrights Canada Press. 